\title{
Thoracic Fracture-Dislocations without Neurologic Injury: 2 Cases Report and their Literature Review
}

\author{
Ribeiro H *, Teixeira R, Fernandes P, Nunes A, Sousa J and Almeida R \\ Hospital São Francisco Xavier, Centro Hospitalar Lisboa Ocidental, Lisboa, Portugal
}

\begin{abstract}
Thoracic spine fracture-dislocation represents $15 \%$ of all thoracic and lumbar fractures. The neurological injury occurs in $80 \%$ of cases, being extremely rare without spinal cord injury. We herein describe the clinical and imagiological features of two patients with fracture-dislocation of the upper thoracic spine without spinal cord injury. The first case is a patient of 60-year-old female with a T3/T4 fracture dislocation associated with a L2 burst type fracture. The patient underwent posterior decompression and reduction with pedicular screw fixation from T2 to T6 and 10 days after posterior transpedicular stabilization with screw in L1 to L3. The second case is a 37-year-old male, presented to us after a motorcycle accident with a T6/T7 fracture dislocation. Reduction and stabilization of the fracture-dislocation was achieved with transpedicular screw fixation in T4 to T6 and T9 to T10, after decompression from T6 to T8. Both patients are asymptomatic with a follow up of 12 and 18 months, Case 1 and Case 2 respectively. The presence of upper thoracic fracture dislocation without neurologic lesions is very rare and biomechanically justifiable when the middle column is separated from the posterior column.
\end{abstract}

Keywords: Thoracic fracture-dislocation; Thoracic spine fractures; Neural sparing

\section{Introduction}

Due to the unique sagittal orientation of facet joints and the presence of the costotransverse articulation of the thoracic spine segment, they are mechanically more stable to axial and horizontal translation $[1,2]$. The spinal canal is narrow, with little free space between the cord and the osseous ring. The thoracic spinal cord also has a relatively sparse blood supply [3-9]. Therefore, any compression or kyphosis in the thoracic spine almost always causes spinal cord injury which is usually severe in the upper thoracic spine. There are only a few cases of severe thoracic spinal fracture-dislocation without neurological symptoms in the literature [10-24]. Here, we report two case reports with a complete fracture-dislocation of thoracic spine without neurological deficit. Moreover, we discuss the clinical and radiological features, injury mechanism, treatment of the thoracic spinal fracture-dislocation and provide a review of the literature.

\section{Case Report 1}

A 60-year-old woman presented to us after a 4 meters height fall. On admission, the patient was fully oriented with stable vital signs, active movement of the upper and lower extremities, normal anal contractility and sphincter reflex were observed. No neurogenic bladder or fecal incontinence was observed. Plain radiographs and computed tomogram showed a T3/T4 fracture-dislocation (type C according to $\mathrm{AO}$ classification) with severe translational and rotational displacement and possible medular compression (Figures $1 \mathrm{~A}, 1 \mathrm{~B}$ and $1 \mathrm{C}$ ). CCompression fracture, burst type (A4 according to $\mathrm{AO}$ classification), in the vertebral body of L2 associated with discontinuity of the posterior elements, apparently, without medular compression and fracture of L1/L2/L3 spine processes. There were also fractures involving the right transverse processes between T7 to T10, spines processes from T10 to L1. Additionally, showed multiple rib fractures with lung contusion, bilaterally complicated with pneumothorax and hemothorax, but without respiratory function compromise. There was also a left retro-renal hematoma with indication for conservative treatment. After one day of hospitalization, reduction and stabilization of the fracture-dislocation was achieved with transpedicular screw fixation from T2 to T6, except left pedicle of T4. To increase stabilization we used a cross - link at T4 level.
During surgery we verified a frank amount of liquor drainage due to a bilateral ventral spinal dural tear treated with tissue fibrin glue. Intra-operative neurophysiological monitoring was applied throughout the operation. The significant blood loss from comminuted fracture of the vertebral body was adjusted with two blood transfusions. The postoperative computed tomogram showed good realignment of the dislocated segment (Figures 2A and 2B). There were no postoperative complications. Close neurological follow-up revealed no pathological findings at this stage of the recovery. After 10 days, it was made a posterior stabilization with transpedicular screw fixation in L1 to L3, to fix the burst fracture in L2 vertebral body. In the early postoperative course the patient complained about intense back pain, VAS 9 in 10, with difficult control by opioids. No deteriorated neurological function was observed postoperatively. There was slight decrease lower limbs muscular force, Medical Research Council (MRC) grade 4 power in both lower limbs, we relate to the intensive care myopathy syndrome. The patient was discharged on day 20th after surgery and could walk with one crutch without any brace. At follow-up 6 months later, the patient had discreet back pain, specifically in thoraco-lumbar transition, VAS 3 in 10. At the 1 year follow-up the patient returned to her job and can walk a distance of $3 \mathrm{~km}$ without pain.

\section{Case Report 2}

A 37-year-old male sustained severe spinal injury from a motorcycle accident. On admission, the patient was awake and fully orientated, Glasgow Coma Score 15, hemodynamically stable. He denied numbness and weakness in his extremities. Physical examination revealed that he was neurologically intact without sensory or motor deficits and had

*Corresponding author: Hugo Filipe Marques Ribeiro, Hospital São Francisco Xavier, Centro Hospitalar Lisboa Ocidental, Lisboa, Portugal, Tel: + 935522248 ; E-mail: hribeiro.1990@gmail.com

Received November 11, 2018; Accepted November 20, 2018; Published November 23, 2018

Citation: Ribeiro H, Teixeira R, Fernandes P, Nunes A, Sousa J, et al. (2018) Thoracic Fracture-Dislocations without Neurologic Injury: 2 Cases Report and their Literature Review. J Spine 7: 425. doi: 10.4172/2165-7939.1000425

Copyright: $\odot 2018$ Ribeiro $\mathrm{H}$, et al. This is an open-access article distributed under the terms of the Creative Commons Attribution License, which permits unrestricted use, distribution, and reproduction in any medium, provided the original author and source are credited. 

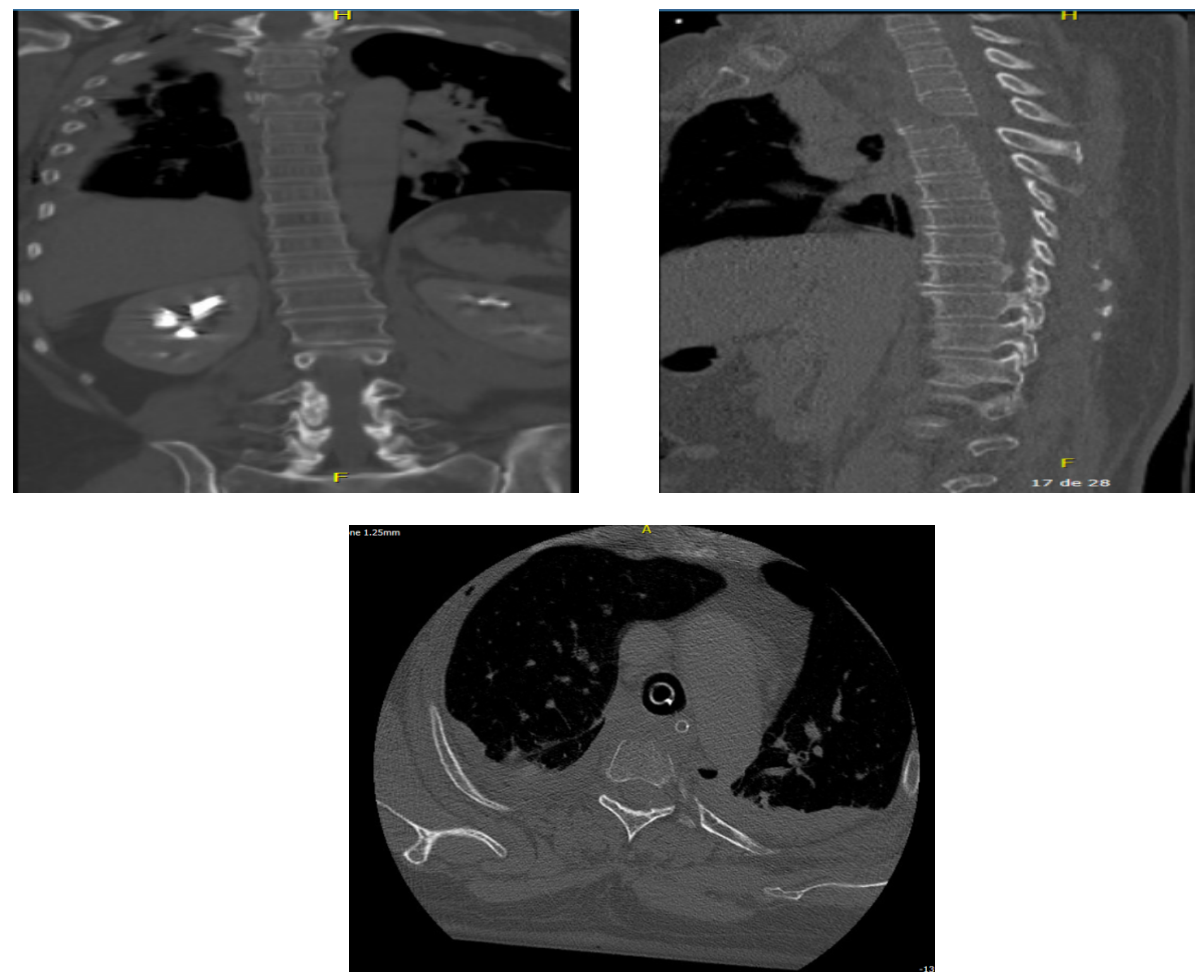

Figure 1: (A) Pre-operative coronal CT scan showing T3/T4 fracture dislocation. (B) Pre-operative sagital CT scan showing T3/T4 fracture dislocation. (C) Pre-operative axial CT scan showing the left pedicle and transverse process fracture, in T4 vertebrae level, and associated bilateral hemothorax.
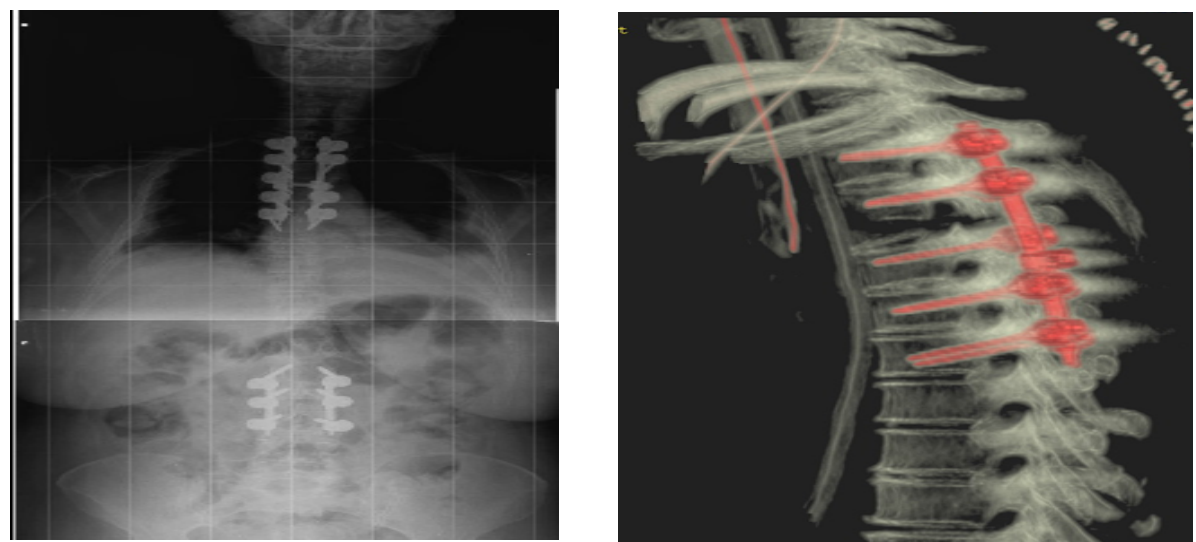

Figure 2: (A) Antero-posterior spine x-ray after open reduction and segmental instrumentation. (B) The 3-dimensional reconstruction revealed the normal alignment.

normal reflexes. Normal anal contractility and sphincter reflex were observed. Computed tomography revealed a T5/T6 complete fracture with lateral displacement of T6. Both vertebrae had left pedicle fracture. There were also fractures involving the right pedicle of $\mathrm{C} 7$, body fracture of T5 and T6, with retropulsion of bony fragments into the spinal canal. Associated injuries were a right-sided 9th rib fracture with pulmonary contusion resulting in right hemo-pneumothorax, which was treated by chest tube insertion, and left kidney contusion. Despite the absence of normal neurological deficits, the spine was considered unstable and an operation was planned on the day of admission (Figures 3A, 3B and $3 C)$.

Reduction and stabilization of the fracture-dislocation was achieved with transpedicular screw fixation from $\mathrm{T} 4$ to $\mathrm{T} 6$ and $\mathrm{T} 9$ to
T10. After decompression from T6 to T8, a dural tear was found and treated with tissue fibrin glue and spongostan ${ }^{\star}$. Realignment of the spine was achieved with 2 rods after placement of transpedicle screws. Finally, we set two cross-links to achieve additional stability. Intraoperative neurophysiological monitoring was applied throughout the operation. The blood loss from comminuted fracture of the vertebral body was solved by two blood transfusions. No deterioration of the neurological function was observed postoperatively. C7 fracture had indication for conservative treatment with cervical collar. The patient was discharged after 2 weeks and could walk without assistance. An anatomic alignment was obtained and maintained at discharge as well as at subsequent follow-up appointments. At 2- month follow-up, the patient complained about sporadic thoracic pain, VAS 4 in 10 , which 

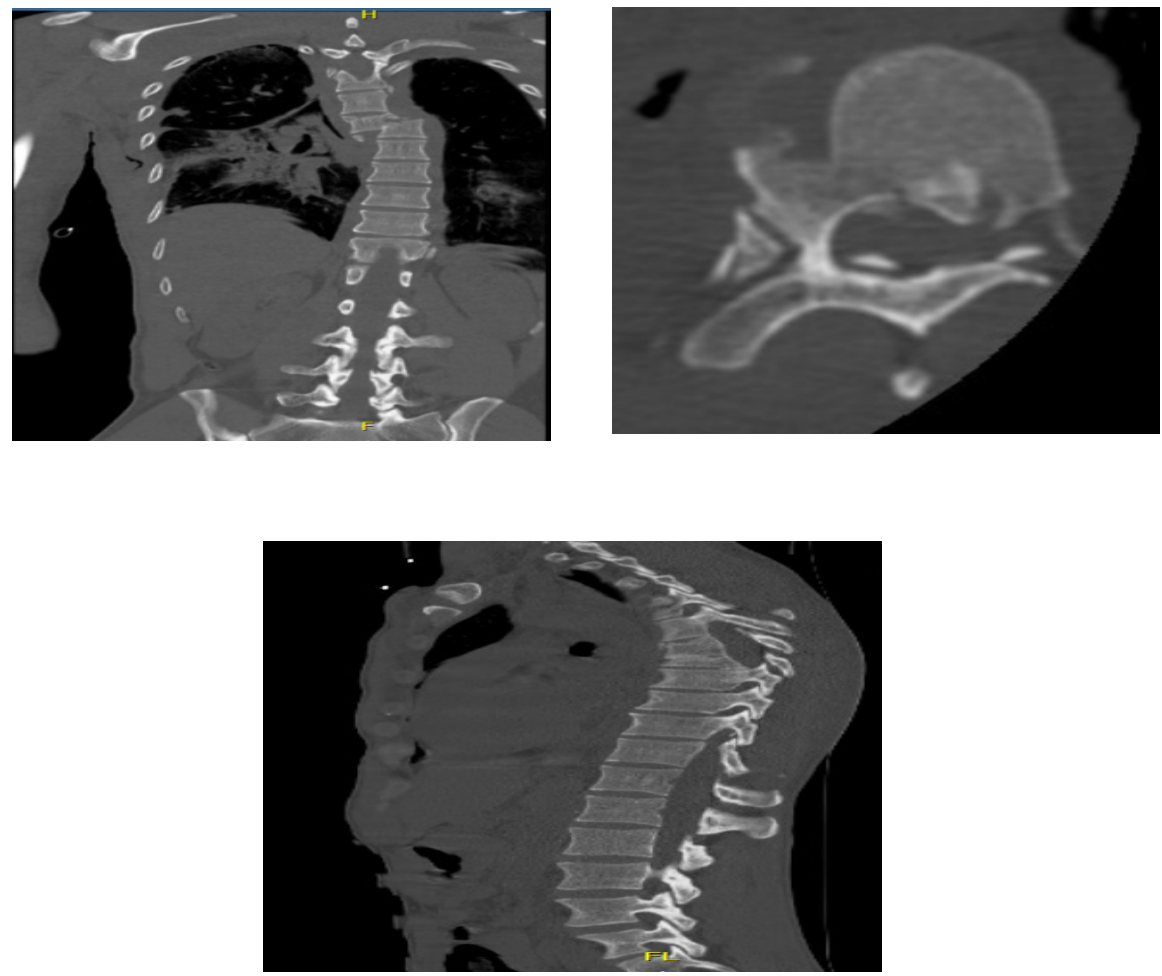

Figure 3: (A) Pre-operative coronal CT scan showing T5/T6 fracture dislocation. (B) Pre-operative sagital CT scan showing T5/T6 fracture dislocation. (C) Pre-operative axial CT scan showing right antero-lateral vertebral body fracture of T5 and T6, with retropulsion of bony fragments into the spinal canal and left pedicle fracture of T5 and T6.
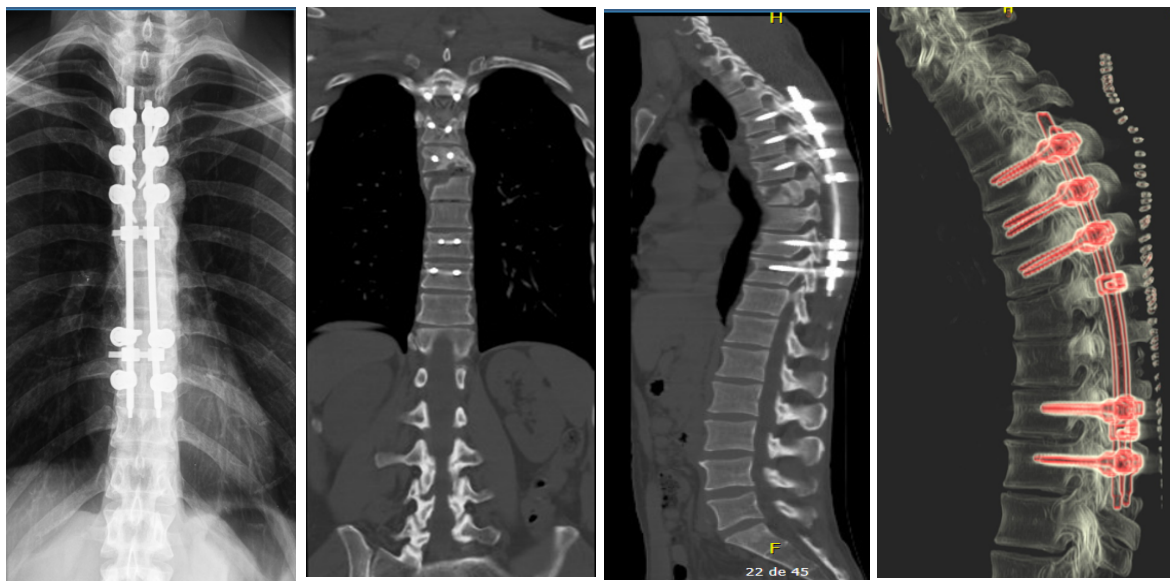

Figure 4: (A) Post-operative antero-posterior $x$-ray showing the reduced lateral dislocation and internal fixation. (B) Post-operative coronal CT scan showing the reduced lateral dislocation and internal fixation. (C) Sagital CT scan after open reduction and segmental instrumentation. (D) The 3-dimensional reconstruction revealed the normal alignment after the insertion of instruments.

improves with analgesics. At the 18-month follow-up, the patient was able to walk $2 \mathrm{~km}$ a day continuously and returned to his job (Figures $4 \mathrm{~A}, 4 \mathrm{~B}, 4 \mathrm{C}$ and $4 \mathrm{D})$.

\section{Discussion}

Fracture-dislocation of the thoracic vertebrae without neurological symptoms is very rare [3]. The rib cage and the orientation of the facet joints provide the thoracic spine with a certain rigidity and protection against injury. Consequently a substantial force is required to produce failure of this spinal region [5]. In 1981 Denis [2] introduced his three-column spine concept. He rated fracture-dislocations as the most biomechanically unstable fractures, being associated with the highest incidence of cord injury among the different fracture types. In 1994 Magerl and coauthors [7] introduced a new classification that have become generally accepted, they define fracture-dislocations as rotational injuries relating to rotation as the main pathogenic force. All these fracture classifications, however, are unanimous in describing fracture-dislocations as failure of all three columns resulting in a high degree of instability. In a thorough study of the biomechanics of spinal injuries, Roaf [9] found the spine to be highly vulnerable to rotational and shear forces.

He found that hyperflexion or hyperextension alone are unlikely to 


\begin{tabular}{|c|c|c|c|c|c|c|c|c|}
\hline S. No & Case authors & Level & Cause & Diagnosis & Pedicle fracture & Body fracture & Dislocation & Treatment \\
\hline 1 & $\begin{array}{l}\text { Gertzbein and } \\
\text { Offierski [10] }\end{array}$ & T5/T6 & Direct trauma & Immediate & Bilateral T6-T8 & None & T5 antero-lateral & $\begin{array}{c}\text { Conservative } \\
\text { (halofemoral traction) }\end{array}$ \\
\hline 2 & Vichard et al. [11] & T8/T9 & Car accident & Immediate & $\begin{array}{l}\text { Right T8 } \\
\text { Left T9 }\end{array}$ & None & T8 lateral & $\begin{array}{l}\text { Conservative (halo } \\
\text { cast) }\end{array}$ \\
\hline 3 & $\begin{array}{c}\text { Weber and } \\
\text { Sutherland [12] }\end{array}$ & T6/T7 & $\begin{array}{l}\text { Motorcycle } \\
\text { accident }\end{array}$ & After 2 days & $\begin{array}{l}\text { Bilateral T7-T9 } \\
\text { Right T } 10\end{array}$ & $\begin{array}{c}\text { Fractures } \\
\text { through } \\
\text { T7-T } 10\end{array}$ & T6 lateral & $\begin{array}{c}\text { Operative } \\
\text { (anterior AO-plate, } \\
\text { posterior Luque) }\end{array}$ \\
\hline 4 & Harryman [13] & $\mathrm{T} 6 / \mathrm{T} 7$ & Car accident & Immediate & Bilateral T5-T8 & None & T6 anterolateral & $\begin{array}{c}\text { Operative } \\
\text { (spinal fusion) }\end{array}$ \\
\hline 5 & $\begin{array}{l}\text { Sasson and } \\
\text { Mozes [14] }\end{array}$ & T9/T10 & $\begin{array}{c}\text { Car } \\
\text { accident }\end{array}$ & Immediate & $\begin{array}{l}\text { Bilateral T9 and } \\
\text { T } 10 \\
\text { Bilateral T7-T10 }\end{array}$ & None & $\mathrm{T} 7$ anterolateral & $\begin{array}{c}\text { Conservative } \\
\text { (halofemoral traction) }\end{array}$ \\
\hline 6 & Uriarte et al. [15] & T7/T8 & $\begin{array}{l}\text { Motorcycle } \\
\text { accident }\end{array}$ & Immediate & Bilateral T7-T10 & $\begin{array}{c}\text { Horizontal shear } \\
\text { fracture } T 7\end{array}$ & T7 anterolateral & $\begin{array}{c}\text { Conservative } \\
\text { (halofemoral traction) }\end{array}$ \\
\hline 7 & $\begin{array}{c}\text { Simpson et al. } \\
{[16]}\end{array}$ & T9/T10 & $\begin{array}{l}\text { Motorcycle } \\
\text { accident }\end{array}$ & Immediate & $\begin{array}{c}\text { Bilateral T9, right } \\
\text { T7, left T8 }\end{array}$ & None & T9 anterolateral & $\begin{array}{c}\text { Operative } \\
\text { (Harrington) }\end{array}$ \\
\hline 8 & Krallis et al. [17] & T7/T8 & $\begin{array}{l}\text { Motorcycle } \\
\text { accident }\end{array}$ & Immediate & Bilateral T7 & None & T7 anterolatera & $\begin{array}{l}\text { Conservative } \\
\text { (cast) }\end{array}$ \\
\hline 9 & $\begin{array}{c}\text { Miyasaka et al. } \\
{[18]}\end{array}$ & T6/T8 & $\begin{array}{l}\text { Motorcycle } \\
\text { accident }\end{array}$ & Immediate & Bilateral T9 & $\begin{array}{l}\text { Vertical } \\
\text { fractures } \\
\text { through T6-T8 } \\
\text { and T } 10\end{array}$ & $\begin{array}{l}\text { T6 posterior T7 and } \\
\text { T8 anterolateral }\end{array}$ & $\begin{array}{l}\text { Conservative } \\
\text { (cast) }\end{array}$ \\
\hline 10 & $\begin{array}{c}\text { De Lucas et al. } \\
{[18]}\end{array}$ & T8/T9 & Car accident & Immediate & Right T8 & $\begin{array}{c}\text { Burst fracture } \\
\text { T8 } \\
\text { shear fracture } \\
\text { T9 }\end{array}$ & T8 anterolateral & $\begin{array}{c}\text { Operative } \\
\text { (anterior fusion) }\end{array}$ \\
\hline 11 & $\begin{array}{c}\text { Korovessis et al. } \\
{[20]}\end{array}$ & T5/T6 & $\begin{array}{l}\text { Motorcycle } \\
\text { accident }\end{array}$ & After 6 weeks & Bilateral T5 and T6 & None & T5 lateral & $\begin{array}{l}\text { Operative } \\
\text { (Luque) }\end{array}$ \\
\hline 12 & $\begin{array}{c}\text { Liljenqvist et al. } \\
{[21]}\end{array}$ & T9/T10 & Car accident & Immediate & Left T9 & $\begin{array}{c}\text { Vertical fracture } \\
\text { T9 }\end{array}$ & T9 antero-lateral & Operative \\
\hline 13 & Potter et al. [22] & T4/T5 & Fall & Immediate & $?$ & $?$ & T5 anterior & Operative \\
\hline 14 & Anthes et al. [23] & T4/T6 & $\begin{array}{l}\text { Motorcycle } \\
\text { accident }\end{array}$ & Immediate & $?$ & $\begin{array}{l}\text { Comminute } \\
\text { anterior } \\
\text { wedging T4 }\end{array}$ & $?$ & $?$ \\
\hline 15 & Jiang B et al. [24] & T6/T7 & $\begin{array}{l}\text { Motorcycle } \\
\text { accident }\end{array}$ & Immediate & Bilateral T6/T7 & $?$ & T6 antero-lateral & Operative \\
\hline
\end{tabular}

Table 1: Data compiled from the 15 previously published cases of thoracic fracture dislocation with neural sparing

create a fracture-dislocation, but that in association with a rotational force, failure of all three columns becomes far more likely. Depending on the additional compressive impact, fractures of the vertebral bodies may occur. Most thoracic fracture dislocations with neural sparing occurred between T-6 and T-10 Miyasaka and coauthors [18-24], explained this occurrence by the fact that in this area the spinous processes extend farther inferiorly than in any other part of the spine. Consequently, they stated, strong shear forces would be concentrated in the middle column, leading to fractures of either pedicle and preservation of the spinal canal. So spontaneous spinal decompression is considered to be the main mechanism [16] and the ribcage helps maintain the stability of an injured thoracic spine, decreasing the risk of neurological injury [13]. In this two cases there was synchronous pedicle fractures, case report 1 with fracture dislocation in T3/T4 and bilateral pedicle fracture in T3/T4 and in case report 2 with fracture dislocation in T5/T6 and left pedicle fracture in T5/6. This is the key mechanism by which the spinal cord did not shift and spinal cord injury did not occur.

There are two different patterns of dislocation that occur depending on the direction of the force experienced by the spinal column. One is anterior-posterior $[14,16,18-24]$ and the other is lateral or rotational dislocation $[10,12,13,15,16]$. In this series, the dislocation in the case 1 was secondary to anterior-posterior shear force. In contrast, the dislocation in case 2 was due to forced flexion combined with rotation. In Table 1, the key data of all 15 reported cases of thoracic fracturedislocation without neurological deficit have been compiled. Almost all thoracic fracture-dislocation with neural sparing occurred between
T6 and T9, except 3 of the 15 reported cases. Which is in accordance with the findings of Hanley and Eskay [8], most fracture-dislocations occurred between T6 and T9 because of horizontal orientation of the vertebrae around the apex of the thoracic kyphosis. Table 1 indicates that the most of the thoracic fracture-dislocation resulted from motor accident (13 out of 15), like the second case report. And only one case described as a fall from a height like our first case report. High-velocity impact with considerable high energy may be the main pattern of injury leading to thoracic fracture-dislocation without neurological deficits. Table 1 shows that fractures of the pedicle (13 out of 15 cases, and the other two are unknown) lead to separation of the posterior from the middle column and avoidance of cord injury by maintaining the spinal canal. So fracture of the pedicle is a precondition for avoiding spinal cord injury. Currently, there are no clear-cut guidelines for the treatment of thoracic fracture-dislocations (Table 1) without any neurological deficits. Several case studies have treated these patients with halo-femoral traction and bed rest followed by rigid casting $[16,18,10,14,15]$. Closed reduction by means of traction is not only impossible, but also carries the danger of a neurological lesion due to narrowing of the spinal canal during traction. Conservative treatment is the first choice in older patients and in those with underlying diseases or serious complications [18]. The optimum treatment for thoracolumbar fracture-dislocation lesions is decompression followed by reduction and internal fixation if the patient's condition is suitable for surgery. A major challenge in surgical management is achieving reduction and preserving the neurologic function after stabilization. In all our cases, 
reduction of the fracture and dislocation was considered necessary to produce a more biomechanically stable spine, to enhance the possibility of fusion, and to prevent delayed neurologic deterioration. However, reduction entails highly significant risks, especially in neurologically uncompromised individuals with severe thoracic displacement [13].

The optimal surgical approach for decompression and stabilization is controversial. The majority of studies prefer posterior reduction, internal fixation and postero-lateral fusion [15-24]. Posterior reduction and stabilization without anterior fusion increases the risk of loss of reduction, instrumentation failure, and non-union in long-term followup. In addition, attempting to reconstruct the anterior and middle columns through a posterior approach entails a great risk especially in the patient who is neurologically intact. Another method that has been described includes a combined anterior-posterior approach with corpectomy, anterior intervertebral fusion, and subsequent posterior instrumentation. This technique usually involves longer operating times and has a greater risk of surgical complications. Furthermore, it commonly requires two surgical teams and longer postoperative hospital stays and higher postoperative morbidity.

\section{Conclusion}

The two case reports presented here, together with a review of the 15 other reported cases of thoracic fracture-dislocations without spinal cord injury, allow us to conclude that: in the majority of thoracic fracture-dislocations with neural sparing the patients were victims of high energy traumas (motor vehicle accidents), severe thoracic fracture-dislocations may be associated with neural sparing if the middle column is separated from the posterior column, decompression is essential before reduction thoracic spinal fracture-dislocation without neurological deficits.

\section{Conflict of Interest}

None of the authors has any potential conflict of interest.

\section{Informed Consent} report

Informed consent was obtained from all individual participants in this case

\section{References}

1. Bohlman HH, Freehafer A, Dejak J (1985) The results of treatment of acute injuries of the upper thoracic spine with paralysis. J Bone Joint Surg Am 67: 360-369

2. Denis $F$ (1983) The three column spine and its significance in the classification of acute thoracolumbar spinal injuries. Spine 8: 817-831.

3. Bohlman HH (1985) Treatment of fractures and dislocations of the thoracic and lumbar spine. J Bone Joint Surg Am 67: 165-169.

4. Zhang S, Yan T (2017) Severe fracture-dislocation of the thoracic spine without any neurological deficit. World J Surg Oncol 15: 3 .

5. Solera J, Haba A (2015) Fracture-dislocation of the upper thoracic spine without neurologic associated injury: Two cases reports. Trauma Cases Rev 1: 4.

6. Jiang B, Zhu R (2014) Severe thoracic spinal fracture-dislocation without neurological symptoms and costal fractures: A case report and review of the literature. Journal of Medical Case Reports 8: 343.

7. Magerl F, Aebi M, Gertzbein D, Harms J, Nazarian S (1994) A comprehensive classification of thoracic and lumbar injuries. Eur Spine J 3: 184-201.

8. Hanley E, Eskay M (1989) Thoracic spine fractures. Orthopedics 12: 689-696.

9. Roaf R (1960) A study of the mechanics of spinal injuries. J Bone Joint Surg $\mathrm{Br}$ 42: 810-8239.

10. Gertzbein S, Offierski C (1979) Complete fracture-dislocation of the thoracic spine without spinal cord injury. J Bone Joint Surg Am 61: 449-451.

11. Vichard $P H$, De la Salle $R$, Tropet $Y$, Runge M (1983) Fracture luxation complete D8-D9 sans complications neurologiques. Description Idsionelle - Deductions therapeutiques. Rev Chir Orthop 69: 645-648.

12. Weber S, Sutherland G (1986) An unusual rotational fracture dislocation of the thoracic spine without neurologic sequelae internally fixed with a combined anterior and posterior approach. J Trauma 26: 474-479.

13. Harryman D (1986) Complete fracture-dislocation of the thoracic spine associated with spontaneous neurologic decompression. Clin Orthop 207: 64-69.

14. Sasson A, Mozes $G$ (1987) Complete fracture-dislocation of the thoracic spine without neurologic deficit. Spine 12: 67-70.

15. Uriarte E, Elguezabal B, Tovio R (1987) Fracture-dislocation of the thoracic spine without neurologic lesion. Clin Orthop Relat Res 217: 261-265.

16. Simpson A, Williamson D, Golding S, Houghton G (1990) Thoracic spine translocation without cord injury. J Bone Joint Surg $\mathrm{Br} 72$ : 80-83.

17. Krallis P, Psicharis P, Dendrinos G (1992) Fracture-luxation du rachis dorsal 5 grand deplacement sans trouble neurologique: Presentation d'une observation et revue de la littdrature. Acta Orthop Belg 58: 84-87.

18. Miyasaka Y, Satomi K, Sugihara S (1993) Posterior fracture dislocation of the thoracic spine without neurological deficit. A case report and short literature review. Spine 18: 2351-2354.

19. De Lukas JC, Alvarez L, Abril JC, Calvo E (1994) Fracture dislocation of the thoracic spine without neurological lesion. Injury 25: 105-107.

20. Korovessis P, Sidiropoulos P, Dimas A (1994) Complete fracture-dislocation of the thoracic spine without neurological deficit: A case report. J Trauma 36 $122-124$.

21. Liljenqvist U, Halm $\mathrm{H}$, Castro $\mathrm{WH}$, Mommsen U (1995) Thoracic fracturedislocation without spinal cord injury: A case report and literature review. Eur Spine J 4: 252-256.

22. Potter MJ, Little C, MacDonald W (2002) Thoracic fracture dislocation without vertebral clinical signs. Injury 34: 942-943.

23. Anthes TB, Muangman N, Bulger E, Stern EJ (2012) Upper thoracic spine fracture dislocation in a motorcyclist. Curr Probl Diagn Radiol 41: 128-129.

24. Jiang B, Zhu R, Cao Q, Pan H (2014) Severe thoracic spinal fracture-dislocation without neurological symptoms and costal fractures: A case report and review of the literature. J Med Case Reports 8: 34. 